\title{
Analysis of potential field anomalies in Lavrion mining area, Greece
}

\author{
Gregory N. Tsokas*, Alexandros Stampolidis*, \\ Antonis D. Angelopoulos ${ }^{\ddagger}$, and Stefanos Kilias**
}

\begin{abstract}
Mining activities in Lavrion began during the first millennium B.C. after the decline of ancient Athens and then restarted more deliberately during the nineteenth century. Aeromagnetic data from a 1967 survey of the mining area was recompiled, processed, and interpreted for the present study. The original flight lines were digitized and leveled, and the international geomagnetic reference field (IGRF) was removed. The data were inverted by means of a terracing technique that defines separate domains of uniform distribution of physical properties that cause the magnetic anomalies.

The log power spectrum was computed; along with the results of terracing, it suggested the existence of two sources of the magnetic anomaly. The long-wavelength
\end{abstract}

anomaly reflects a large, concealed body that is most probably a granitic intrusion, consistent with local geological evidence. The source of the short-wavelength anomaly is a strongly magnetized body attributed to the net effect of various thin, magnetite-bearing sulfide zones.

The anomalies were then separated in the wavenumber domain. Magnetic susceptibility measurements were made in situ on the exposed parts of the local formations. Three-dimensional models whose effect simulates the observed anomalies were calculated. Results of the modeling show that the large magnetic body is buried at $0.68 \mathrm{~km}$ depth. The small, relatively shallow body is about $0.035 \mathrm{~km}$ thick and buried at $0.6 \mathrm{~km}$ depth. The bodies do not show any corresponding gravity anomaly on the regional Bouguer gravity anomaly map.

\section{INTRODUCTION}

The exploitation of the mines in the Lavrion area contributed to the power of ancient Athens. The Athenian city-state used slaves (mainly war prisoners) to mine lead and silver, which was extracted from the lead ore. The mines were shut down following the decline of Athens and were reopened in the nineteeth century for mining and ore processing operations. The exploitation of mixed sulfide ores continued until the early 1970s when the mines were again shut down.

The area was intensively studied during the nineteeth century, and papers describing the geological setting and the mineralization can be found in the recent literature (e.g., Papanikolaou and Syskakis, 1991).

The original aeromagnetic map of the area was compiled in 1967. Gravity investigations were carried out in 1971 (Makris et al., 1973), which resulted in the compilation of the Bouguer anomaly map. Marinos and Makris (1975) interpreted the magnetic data and concluded that a batholith exists in the eastern part of the peninsula of Attiki beneath the area of Plaka (Figure 1). They also suggested another magnetic body occurs at the contact of the batholith with the overlying formations. This body causes a strong magnetic anomaly on the order of 1200 nanoteslas (nT).

Stavrou (1971) conducted a limited ground magnetic survey north of Plaka that partially covered the 1200-nT anomaly. Several short-wavelength anomalies on the order of $200 \mathrm{~m}$ were detected and were attributed to magnetite-bearing sulfide sills. The magnitude of the remanent magnetization of the magnetite-bearing sulfides was found to be about $0.12 \times$ $10^{9} \mathrm{Am}^{-1} / \mathrm{m}^{3}\left(0.12 \mathrm{emu} / \mathrm{cm}^{3}\right)$. The other formations and minerals of the area had negligible remanent magnetization.

Manuscript received by the Editor February 10, 1997; revised manuscript received December 5, 1997.

*Geophysical Laboratory, Aristotle University of Thessaloniki, 54006 Thessaloniki, Greece. E-mail: gtsokas@geo.auth.gr. Phone: 31-998507; Fax: 31-998528.

$\ddagger$ Dept. of Geophysical Exploration, Institute of Geology and Mineral Exploration, Messogion 70, 11527 Athens, Greece. Phone: 1-7779420; Fax: 1-7752211.

${ }^{* *}$ Department of Geology, National University of Athens, Ano Ilissia, 15784 Athens, Greece. Phone: 1-7284211.

(C) 1998 Society of Exploration Geophysicists. All rights reserved. 
Marinos and Makris (1975) used a 2-D interpretation scheme. They assumed the values of the magnetic susceptibilities of the bodies, which were simulated in their models. Our study is based on their data. However, we redigitized the flight line records and compiled a new total field map. We then transformed, filtered, and inverted the data. Magnetic susceptibility was measured in situ on surface exposures of Lavrion intrusions. Finally, 3-D models of the concealed magnetic bodies were constructed.

\section{GEOLOGICAL SETTING}

The geology of the Attiki peninsula (Figure 1) consists of two tectonic units: the autochthonous unit of Attiki and the allochthonous unit of Lavrion (Marinos and Petrascheck, 1956). The autochthonous unit comprises the upper and lower marble horizons, separated by calcic mica schists. Fossil dating indicates a late Triassic age for the lower marble horizon. The allochthonous unit constitutes an overthrusted nape that includes low-grade phyllites, schists, greenstones, and crystalline limestones. According to Papanicolaou (1986), this allochthonous unit constitutes a chaotic melange of late
Creataceous-early Triassic age. The overthrust was directed from north to south and caused intensive mylonitization along the boundary that separates the allochthonous and autochthonous units.

Younger granites, granodiorites, and porphyritic granodiorites occur in the form of laccoliths, pipes, dikes, and sills over much of the eastern part of the peninsula (Papanikolaou and Syskakis, 1991). These features may indicate the existense of a granitic batholith at depth. Furthermore, extensive contact metamorphism in the area may have resulted from the intrusion of this batholith. Such phenomena are evident in Plaka, where calcic schists and marbles have been metasomatized by hydrothermal activity to produce skarn-type alteration haloes along the contacts with granodioritic bodies.

On the basis of K/Ar dating of biotite, the age of the granitic bodies in Lavrion were determined to be 10 million years by Marakis (1968) and $8.8 \pm 0.5$ million years by Marinos (1971).

\section{DATA USED}

The aeromagnetic survey of Lavrion was conducted in 1967 by ABEM, a geophysical contractor, on behalf of the Institute
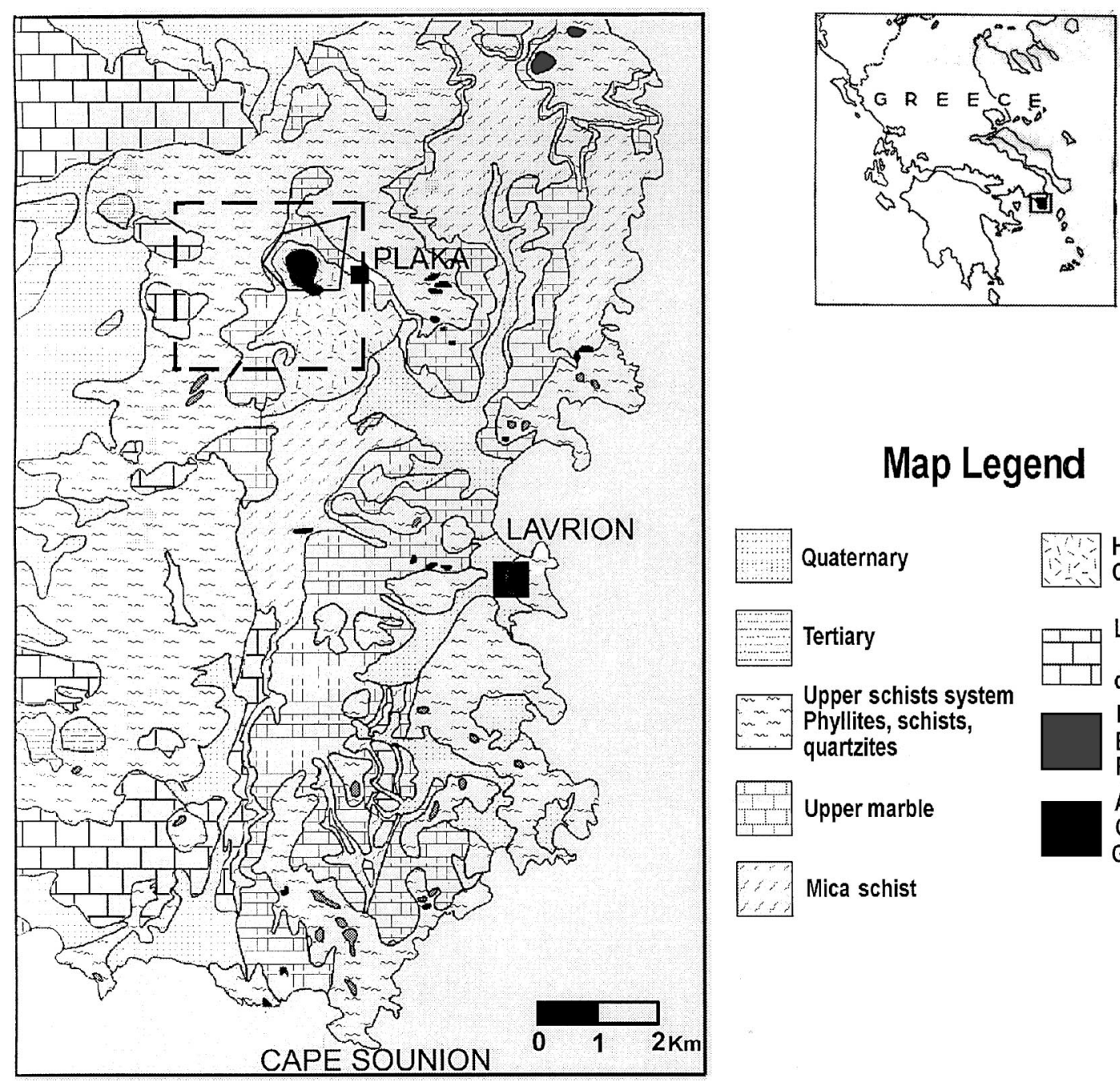

\section{Map Legend}

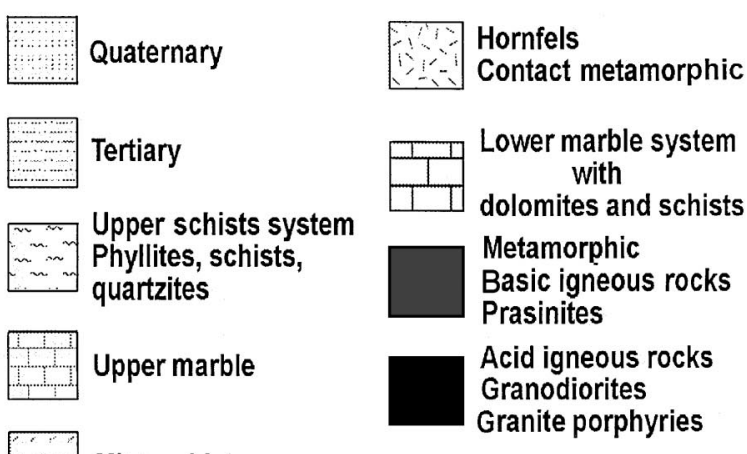

Mica schist

FIG. 1. Geological map of the southeastern part of the peninsula of Attiki. The general area is called Lavrion, but a small port city bears the same name. The large intrusion area is outlined by a dashed line; the highly magnetized body, by a solid line. 
of Geology and Mineral Exploration (IGME) of Greece. The survey was flown at an average mean terrain clearance of $270 \pm 50 \mathrm{~m}$, and the flight lines were spaced $1 \mathrm{~km}$ apart. One tieline was flown. The original analog records were digitized in the framework of the present study. The resulting total-intensity field profiles were sampled every $50 \mathrm{~m}$. The international geomagnetic reference field (IGRF) of epoch 1965 was extracted. Line leveling was performed to adjust the neighboring flight lines. The map compiled from this data set is shown in Figure 2.

The Bouguer anomaly map used in this study was extracted from the respective map of Greece. This was compiled by Lagios et al. (1988). It was based on the data of Makris et al. (1973), complemented by the results of more recent surveys.

\section{FILTERING, TERRACING THE MAGNETIC FIELD, AND ESTIMATING DEPTH}

The data were transformed to the wavenumber domain, and the azimuthally averaged logarithmic power spectrum was computed (Figure 3). The log spectrum shows two discernible parts, indicating two sources exist. For each part, the spectral slope was measured according to the depth estimation method of Spector and Grant (1970). The spectral slope technique was applied to deduce a depth estimate of about $680 \mathrm{~m}$ for the upper surface of the body. Approximately the same depth estimate was inferred for the high-wavenumber portion. This suggests that the small body is very thin but strongly magnetized, compatible with the existence of skarn-type mineralization appearing in thin zones in the marbles as detected by drilling (Stavrou, 1971). Marinos and Makris (1975) also suggest that a magnetite-bearing ore body sits on the batholith.

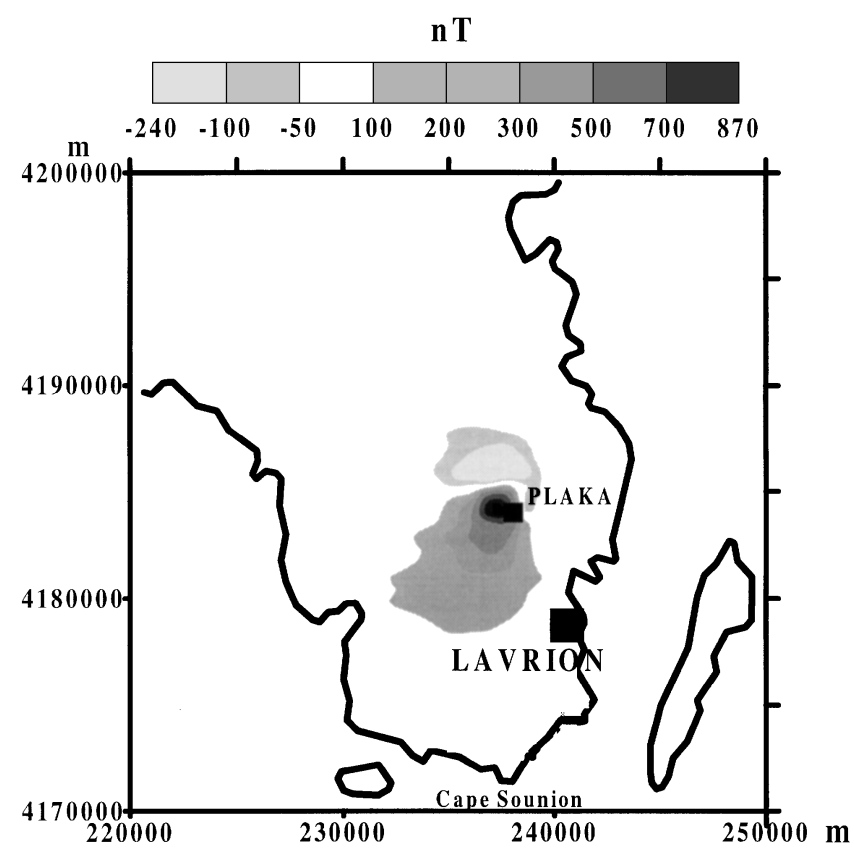

FIG. 2. Magnetic total field map of Lavrion, compiled from the digitized analog records after resampling every $50 \mathrm{~m}$ and removing the IGRF. Values are in nT. The universal transjection mercatoric (UTM) projection was used, and the coordinates refer to zone 34 of the particular system.
Filtering in the wavenumber domain was carried out to separate the effect of the discernible sources using the software of Hildenbrand (1983). The low-pass filtered map shown in Figure 4a was constructed using a full-pass threshold of $5000 \mathrm{~m}$, while the roll-off ramp was set to $1000 \mathrm{~m}$ (i.e., from $4000 \mathrm{~m}$ ). On the other hand, the high-pass filtered map was constructed using the same parameters but in the opposite sense (Figure 4a). That is, the full-pass threshold was set to $4000 \mathrm{~m}$ and the roll-off ramp extended up to $5000 \mathrm{~m}$.

A well-shaped anomaly that reflects the effect of a relatively large body is present in the low-pass filtered map. This is presumably a granitic batholith. A relatively small wavelength anomaly is observed in the high-pass filtered map. The small anomaly partially overlaps that associated with the batholith.

Cordell and McCafferty (1989) present an iterative method to transform the potential field data into uniform domains separated by abrupt domain boundaries. The method is called terracing, and it comprises a mapping of the physical properties that caused the anomalous field. In other words, it is an inversion scheme that produces geological boundaries. Although the method is directly applicable to the gravity field data, the magnetic data are first transformed to pseudogravity using the software of Hildenbrand (1983), who uses the specific formula given by Lourenco (1973). The intensity of magnetization was set to $44.6 \times 10^{-3} \mathrm{Am}^{-1}$, which is based on the average value of the ambient field and the susceptibility contrast chosen by Marinos and Makris (1975). The declination and inclination of the magnetization vectors were set to $0^{\circ}$ and $54^{\circ}$, respectively. These are the present values of the elements of the earth's magnetic field in Greece. In other words, the magnetization vector was considered along the present-day direction. This is a reasonable assumption and comprises the closest approximation that can be achieved since the magnetic sources are concealed. Further, the final goal is the construction of the terraced field. This procedure is controlled by the sign of the curvature of the field; thus, the actual magnitude is not as important.

We used Phillips' (1992) implementation for the terracing inversion. The result is depicted in Figure 5a, where it can be seen that two main domains have been deduced. We assume the boundaries of these domains delinate more-or-less the lateral extent of the concealed magnetic bodies. Therefore, we

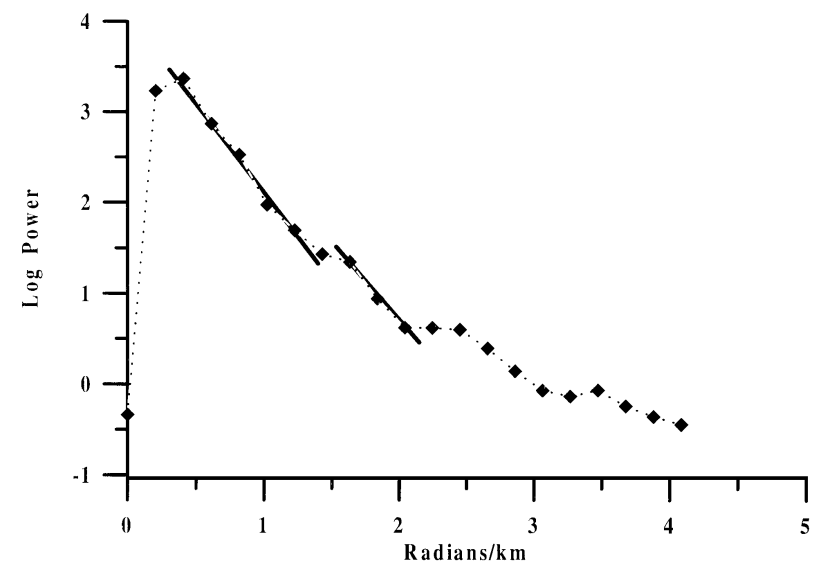

FIG. 3. Azimuthally averaged logarithmic power spectrum of the magnetic total field data. The fitted straight-line segments are also shown. 
can intervene and draw straight-line segments to approximate the plan view of the bodies by polygons. This procedure comprises part of the interpretational scheme; the result is shown in Figure 5 as a solid and a dashed line.

\section{INTERPRETATION OF THE ANOMALOUS MAGNETIC FIELD}

The preceding analysis indicates the anomalous magnetic field is caused by two discernible sources. The long-wavelength part of the field shown in Figure 4a can be attributed to a regional-scale igneous intrusive body. The short-wavelength
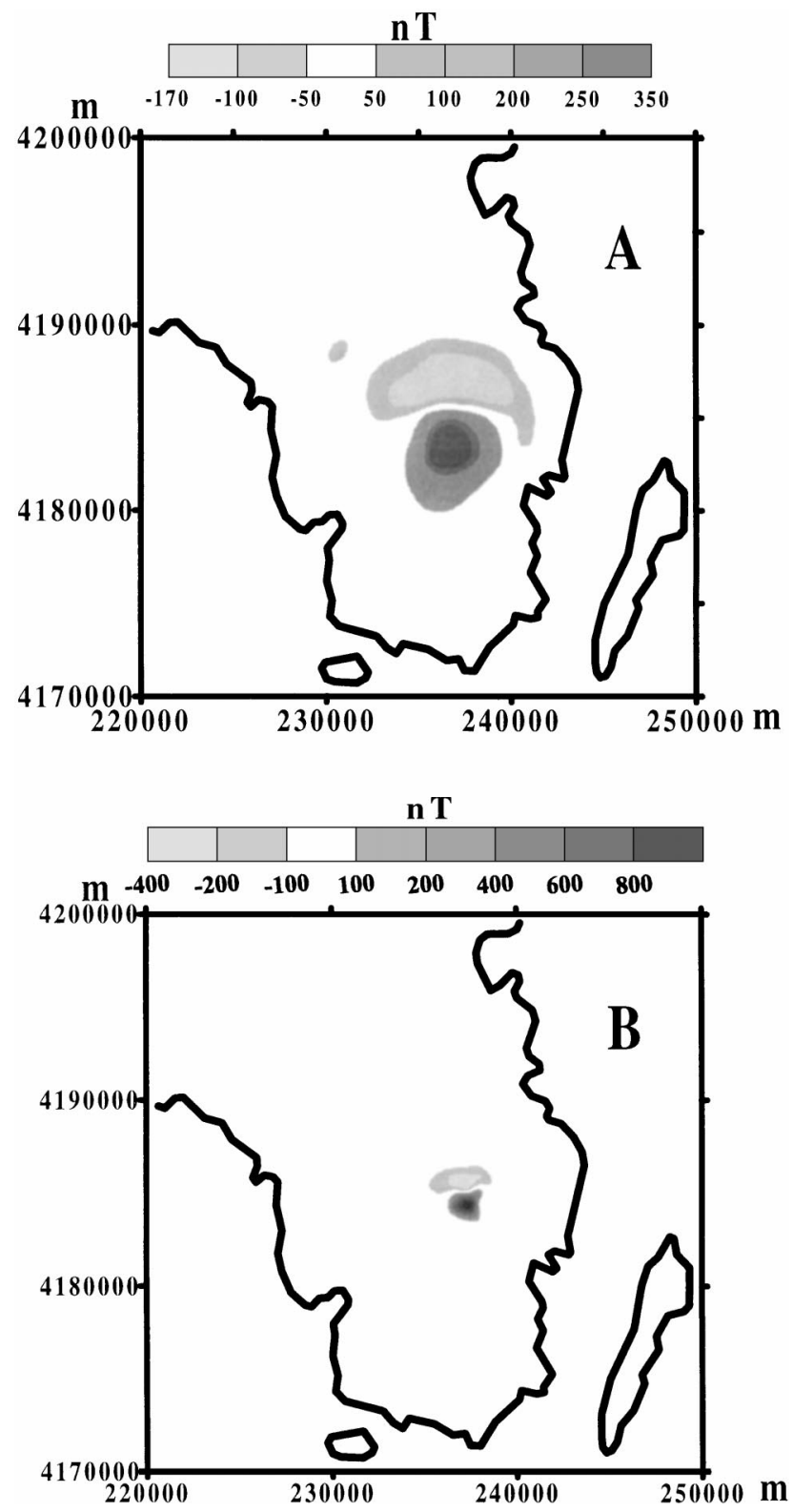

FIG. 4. (a) Low-pass filtered map of the magnetic total field in grayscale mode. The cut-off wavelength was set to $5000 \mathrm{~m}$, while the roll-off ramp is $1000 \mathrm{~m}$ long. (b) High-pass filtered map of magnetic total field in grayscale mode. The same cut-off parameters were used as those for the construction of the low-pass map but in the opposite sense. part of the field has a high magnitude on the order of $1200 \mathrm{nT}$ (peak to peak) and reveals the presence of a highly magnetic source that may represent some sort of mineralization.

Concerning the large body, Marinos and Makris (1975) assume an apparent susceptibility of $3 \times 10^{-3} \mathrm{cgs}$ units (0.0377 SI) and only induced-type magnetization in constructing their 2-D model. We conducted apparent susceptibility measurements at various granitic exposures on the surface and also in the underground excavation fronts shown in some ancient mining tunnels. The results, including relevant measurements of the other geological units, are shown in Table 1. However, the value measured for the granodiorite is an order of magnitude less than the one assumed by Marinos and Makris (1975). The susceptibility value is large for the magnetitebearing sulfides, as expected. The other units, which presumably host the magnetic bodies, exhibit negligible susceptibility values.

By using the results inferred from terracing the field, we were able to constrain the shape of the cross-section of the disturbing body and its areal extent. A polygonal cross-section was assumed; thus, we considered the disturbing body can be simulated by a vertical-sided prism (Figure 6a). The upper surface of the prism was placed $0.68 \mathrm{~km}$ below the flight path, as inferred by the spectral slope estimate. The method of Bhattacharrya (1964) was used to calculate the effect of the prism, whose

Table 1. Apparent magnetic susceptibility values measured at exposures of marble, schists, granodiorites, pyrrhotites, and sulfide ores in the area of Lavrion.

\begin{tabular}{lcc}
\hline Formation & $\begin{array}{c}\text { Apparent susceptibility } \\
\times 10^{-3} \text { SI units }\end{array}$ & Standard Deviation \\
\hline Granodiorite & 9.00 & 1.10 \\
Schists & 0.23 & 0.05 \\
Marble & 0.03 & 0.02 \\
Pyrrhotite & 37.70 & 4.90 \\
Sulfide ores & 6.92 & 1.17 \\
\hline
\end{tabular}

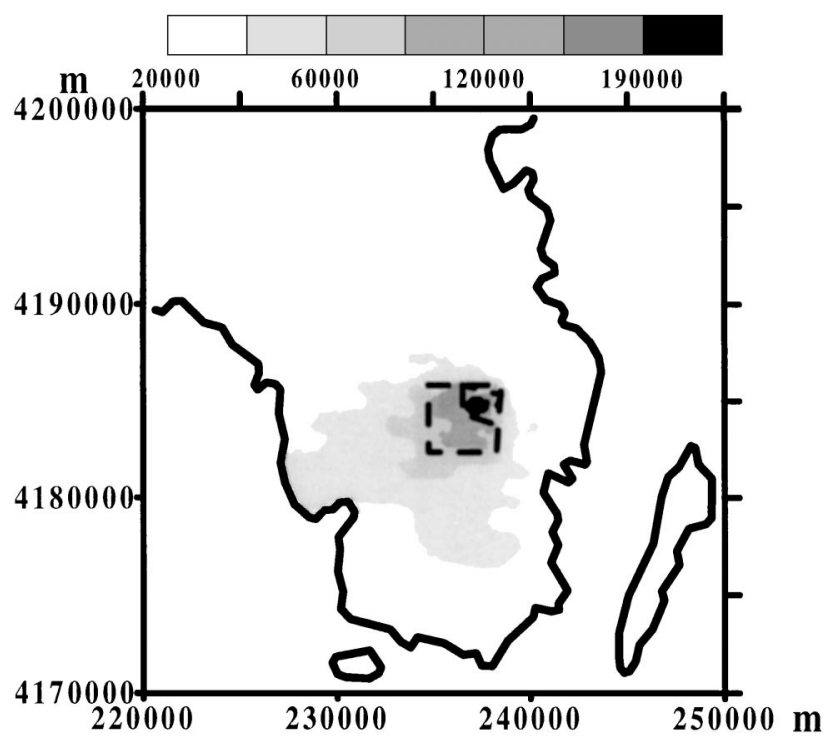

FIG. 5. The result of the terracing inversion. Units are arbitrary. The dashed polygonal lines represent the considered approximation of the edges of the buried bodies. 
susceptibility contrast was initially put at the level measured for the granites on the surface. The depth extent of the body was considered $4 \mathrm{~km}$. The described setting could not produce an effect similar in magnitude to the observed effect. Thus, altering the susceptibility of the body, we reached a value of $4 \times$ $10^{-2}$ (SI), which is the same order of magnitude as that used by Marinos and Makris (1975). The computed effect along the
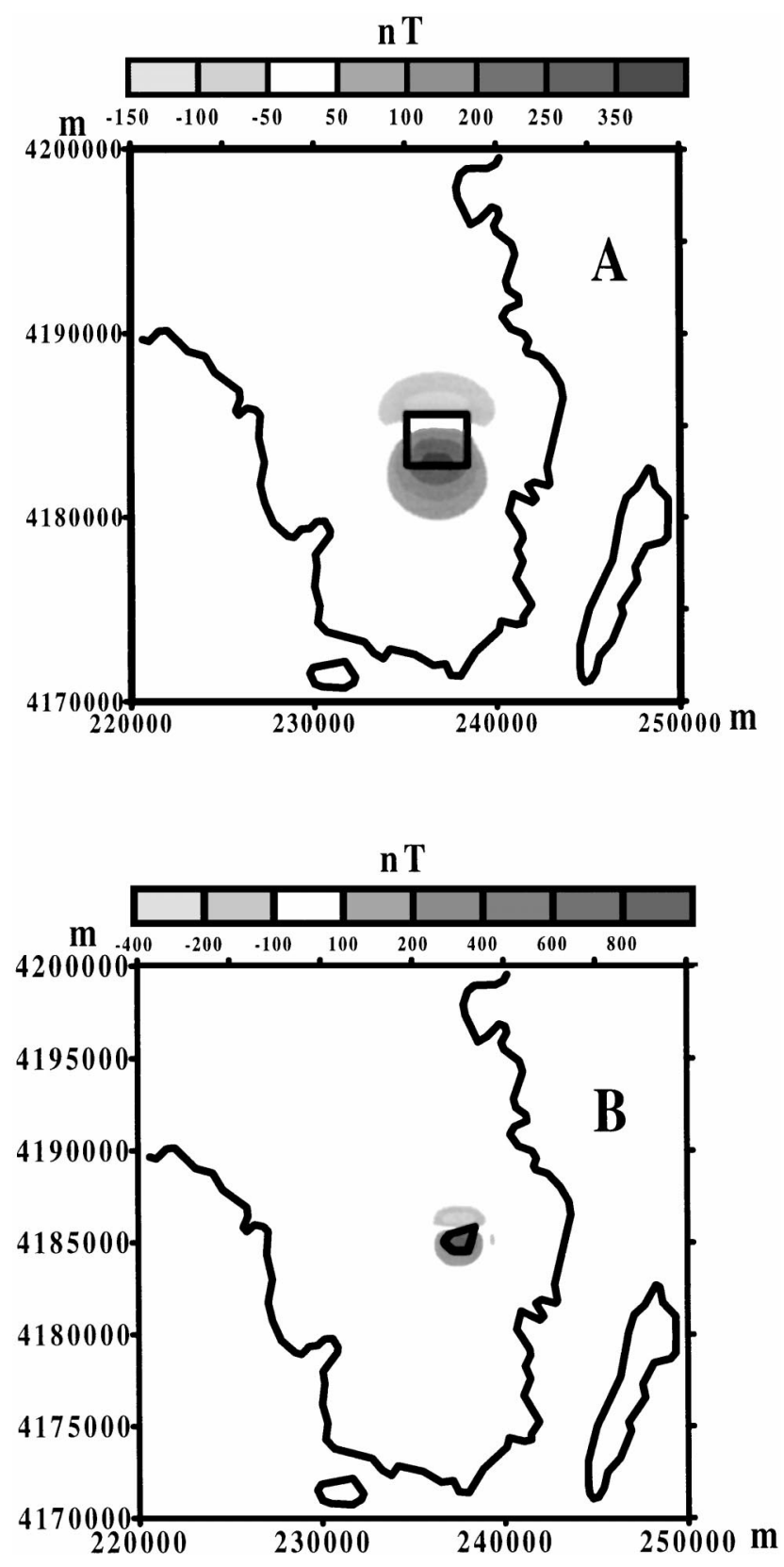

FIG. 6. (a) The computed effect of a vertical-sided prism whose plan view is depicted by the bold polygonal line. The upper surface of the prism is at $0.68 \mathrm{~km}$ depth, while its bottom surface lies at $4.68 \mathrm{~km}$. The magnetic susceptibility contrast is $4 \times 10^{-2}(\mathrm{SI})$. The prism is considered responsible for the long-wavelength band of the anomalous field. (b) The bold line depicts the horizontal plan view of a prism buried at $0.60 \mathrm{~km}$ depth and extending downward for $35 \mathrm{~m}$. The prism simulates the pyrrhotite ore deposits, which have strong remanent magnetization. plan view of the prism which simulates the disturbing body is shown in Figure 6a. The magnitude and the pattern of the computed effect is in good agreement with the observed field of Figure 4a.

The small-wavelength part of the anomalous field (Figure 4b) can be attributed to a highly magnetized body that lies at approximately the same depth as the upper surface of the large intrusion, as determined by the spectral slope estimates. The measured magnetic susceptibility of the magnetite-bearing sulfides alone is inadequate to account for the magnitude of the anomaly. This is in accordance with the considerations of Stavrou (1971), who measures a strong remanent component in magnetite-bearing sulfide samples on the order of $0.12 \times$ $10^{9} \mathrm{Am}^{-1} / \mathrm{m}^{3}$ (equivalent to $0.12 \mathrm{emu} / \mathrm{cm}^{3}$ ). Unfortunately, the angles of the magnetic vector were not measured at that time. However, the anomalies recorded by the surface measurements of Stavrou (1971) indicate an eastward declination of about $30^{\circ}$. Furthermore, Marinos and Makris (1975) adopt an inclination of $80^{\circ}$. Both the surface measurements and the small-wavelength part of the field (Figure 4b) indicate the inclination might be slightly higher. Thus, we considered an inclination angle of $85^{\circ}$ and adopted the former estimates for the other elements of the field.

Boreholes drilled for exploration purposes (Stavrou, 1971) intersected parallel magnetite-bearing sulfides zones of varying thickness at different burial depths to agree with results obtained by Leleu et al. (1973). The overall thickness was estimated to be about $35 \mathrm{~m}$ at a depth of $300 \mathrm{~m}$. This depth is in fairly good agreement with the spectral slope estimate because the calculations were performed for the flight-line altitude (i.e., $275 \mathrm{~m}$ on average, above the ground surface).

Using all the constraints discussed above along with the delineation of the edges of the disturbing body provided by the terracing, a vertical-sided prism was assumed whose crosssection is shown in Figure $6 \mathrm{~b}$ in plan view. The upper surface of the prism was placed at $600 \mathrm{~m}$ depth, and its thickness was set to $35 \mathrm{~m}$. Thus, this thin prism lies fairly close to the large intrusion. The computed effect of the prism is also shown in Figure $6 \mathrm{~b}$, and it is in good agreement with the observed field (Figure 4b).

The regional geological setting indicates the large body considered in this study is probably a granitic intrusion, and our analysis of its magnetic properties is consistent with its interpretation. However, at the construction of the appropriate model, its magnetic susceptibility was set an order of magnitude higher than the one measured at the exposures. This was necessary because no fit could be achieved between the observed and calculated fields. This contradiction leads to the conclusion that the surface granitic exposures are probably highly altered by weathering and/or other processes, or that the large body has different composition than the exposed granitic rocks.

The model considered for the highly magnetic ore lying above the intrusion is an approximation. It may account for the overall effect of various small mineralization zones, which are seen as an ensemble. More detailed studies are warranted using surface magnetic or electromagnetic surveys combined with drilling.

The projection of the large body on the ground surface is depicted by a dashed line back in Figure 1; the small body is shown by a solid line. The highly magnetic body is inferred to be in contact with the granitic intrusion. This is expected for 
skarn-type mineralization and supports the considerations of our study.

Further, small acid igneous rock outcrops are scarce on Figure 1 . These bodies may comprise apophyses from the central and large intrusion, which may have been translated as well. The larger of these detached pieces is in contact with the highly magnetic body.

Unfortunately, the regional gravity data are not detailed enough to be useful.

\section{CONCLUSIONS}

A large intrusion is interpreted to be the source of the longwavelength part of the magnetic anomaly in the Lavrion mining area in southeastern Attiki. This intrusion exhibits no gravity expression on the existing course grid of gravity measurements. The short-wavelength part of the field may be the result of magnetite-bearing, skarn-type mineralization that lies buried on top of the large intrusion. Because of the relative position of the two magnetic sources, the mineralization is probably related to contact metamorphic phenomena caused by the intrusion of the buried granitic batholith. In view of the existence of skarn-type polymetallic mineralization exposed at the surface of the Plaka area, the postulated existence of additional mineralization occurring at a depth of $300 \mathrm{~m}$ on top of a large granitic batholith presents interesting exploration targets.

\section{ACKNOWLEDGMENTS}

We thank our colleague, Panagiotis Tsourlos, for his careful reading of the manuscript. We also thank the reviewer, M. O. Kleinkopf, and the associate editor, G. R. Keller, for their fruitful comments, which considerably enhanced the paper.

\section{REFERENCES}

Bhattacharrya, B. U., 1964, Magnetic anomalies due to prism shaped bodies with arbitrary polarisation: Geophysics, 29, 517-531.

Cordell, L., and McCafferty, A. E., 1989, A terracing operator for physical property mapping with potential field data: Geophysics, 54, 621634.

Hildenbrand, T. G., 1983, FFTFIL: A filtering program based on two dimensional Fourier analysis: USGS Open-File Report 83-237.

Lagios, E., Hipkin, R. G., Angelopoulos, A., and Nikolaou, S., 1988, The gravity anomaly map of Greece-A recompilation: Institute for Geology and Mineral Exploration (Greece).

Leleu, M., Morikis, A., and Picot, P., 1973, Sur des mineralisations de type skarn au Laurium (Greece): Mineral Deposita, 8, 259-263.

Lourenco, J. S., 1973, Analysis of three-component magnetic data: Ph.D. thesis, Univ. of California at Berkeley.

Makris, J., Mavridis, L. N., Menzel, H., Stavrou, A., and Veis, G., 1973 , The gravity field of Attika, the Peloponnese and Kithira, Greece: Zeitschrift für Geophysik, 39, 929-936.

Marakis, G., 1968, Observations on the sulphide mineralization of $\mathrm{Cy}$ clades: Ann. Geol. Pays Hellen., 19, 695-700.

Marinos, G., 1971, On the radio-dating of rocks in Greece: Ann. Geol. Pays Hellen., 23, 175-182.

Marinos, G., and Makris, J., 1975, Geological and geophysical considerations of new mining possibilities in Laurium, Greece: Ann. Geol. Pays Hellen., 27, 1-10.

Marinos, G., and Petrascheck, W. E., 1956, Lauvium: Institute for Geology and Mineral Exploration (Greece).

Papanikolaou, D., 1986, Late Cretaceous paleogeography of the Metamorphic Hellenides: Geol. Geoph. Res. IGME Special issue, 315328.

Papanikolaou, D., and Syskakis, D., 1991, Geometry of acid intrusives in Plaka, Laurium and relation between magmatism and deformation: Bull. Geol. Soc. Greece, 35, No. 1, 355-368.

Phillips, J. D., 1992, TERRACE: A terracing procedure for gridded data, with FORTRAN programs and VAX command procedures, UNIX C-Shell and DOS implementations: USGS Open-File Report 92-5.

Spector, A., and Grant, F. S., 1970, Statistical models for interpreting aeromagnetic data: Geophysics, 35, 293-302.

Stavrou, A., 1971, On the reconnaissance magnetic survey in Villia, Lavrion: Institute for Geology and Mineral Exploration (Greece). 